\title{
Capecitabine in Combination with Docetaxel in First Line in HER2-Negative Metastatic Breast Cancer: an Observational Study
}

\author{
Renáta Kószó $^{1}$ - Dóra Sántha ${ }^{1}$ - László Büdi ${ }^{2}$. József Erfán ${ }^{3}$ • Károly Győrfy ${ }^{4}$. \\ Zsolt Horváth $^{5}$ • Judit Kocsis ${ }^{6}$ - László Landherr ${ }^{7}$ - Erika Hitre ${ }^{8}$ - Károly Máhr ${ }^{9}$ • \\ Gábor Pajkos ${ }^{10} \cdot$ Zsuzsanna Pápai $^{11} \cdot$ Zsuzsanna Kahán $^{1}$
}

Received: 26 June 2016 / Accepted: 11 October 2016 / Published online: 22 October 2016

(C) Arányi Lajos Foundation 2016

\begin{abstract}
Due to the limited experience with capecitabine plus docetaxel (XT) combination in the first-line treatment of metastatic breast cancer in Hungary, the main objective of the study was to analyze the effectiveness and tolerability of XT therapy. A prospective, open-label, non-randomized, single-arm, multicenter, observational study was designed. All female patients were eligible whose metastatic breast cancer could be treated with the XT protocol according to the summary of product characteristics of the drugs. The median progression free survival was $9.9 \pm 3.0$ months. Time to treatment failure was $4.6 \pm 5.1$ months on average. The overall response rate was $28.9 \%$, the clinical benefit rate was $73.3 \%$. The treatment was discontinued in $35.6 \%$ of patients due to disease progression and in $20.0 \%$ due to adverse events (AE). 33 patients with a total of 73 AEs have been reported, and 13 of them had serious adverse events (SAE). The efficacy and the safety profile of XT chemotherapy proven in the study are consistent with the results demonstrated in randomized trials. First-line XT chemotherapy effectively improves the PFS in metastatic breast cancer.
\end{abstract}

Zsuzsanna Kahán

kahan.zsuzsanna@med.u-szeged.hu

1 Department of Oncotherapy, University of Szeged, Korányi fasor 12, Szeged 6720, Hungary

2 Borsod-Abauj-Zemplén County Hospital, Szentpéteri kapu 72-76, Miskolc 3526, Hungary

3 Szabolcs-Szatmár-Bereg County Jósa András Hospital, Szent István u. 68, Nyíregyháza 4400, Hungary

4 Kaposi Mór Teaching Hospital, Tallián Gy. u. 20-32, Kaposvár 7400, Hungary

5 Medical Center, University of Debrecen, Nagyerdei krt. 98, Debrecen 4032, Hungary
Keywords Capecitabine $\cdot$ Docetaxel $\cdot$ HER2-negative metastatic breast cancer $\cdot$ Toxicity

\section{Introduction}

Capecitabine is a derivative of 5'-deoxy-S-fluoro uridine carbonate, which is absorbed from the gastrointestinal tract invariably as a prodrug [1]. To the metabolism of capecitabine into active 5-FU, three activation steps are needed [2]. In the final process step, the thymidine phosphorylase (TP) enzyme plays a key role in creating the active form. The enzyme is present in normal and tumor cells, however, since the expression of TP in most tumor tissues is much higher than in normal tissues, the prodrug's activation and concentration is increased in cancers as compared to that in healthy tissues. This results in relatively selective effect and lower systemic toxicity than the use of intravenous 5-FU [3-5].

In addition to the selective activation of capecitabine in tumors $[1,2]$, synergy with other anticancer agents such as the taxanes is reported [6]. Docetaxel blocks the

6 3rd Department of Internal Medicine, Semmelweis University, Kútvölgyi út 4, Budapest 1125, Hungary

7 Uzsoki Hospital, Uzsoki u. 29-41, Budapest 1145, Hungary

8 National Institute of Oncology, Ráth György u. 7-9, Budapest 1126, Hungary

9 Zala County Hospital, Zrínyi M. u. 1, Zalaegerszeg 8900, Hungary

10 Bács-Kiskun County Hospital, Nyíri u. 38, Kecskemét 6000, Hungary

11 Hungarian Army Medical Center, Róbert Károly körút 44, Budapest 1134, Hungary 
breakdown of the microtubule system allowing cell division and multiplying, resulting in cell death [8]. It also affects the development of non-cancer cells such as the blood cells, which may cause side effects. According to human cancer xenograft studies, Docetaxel induces TP activity in cancer cells, thereby enhancing the efficacy of capecitabine, thus potentiating the inhibition of tumor growth in colon and breast cancer models [6].

Capecitabine (Xeloda ${ }^{\circledR}$, Roche) plus docetaxel (XT) therapy is a reasonable choice for the treatment of metastatic breast cancer (MBC) patients who have previously received anthracyclines [7]. The main objective of the XEBRA study was to assess safety and efficacy of XT treatment under reallife circumstances.

\section{Patients and Methods}

All the procedures followed were in full accordance with the ethical standards of the responsible committees on human experimentation (institutional and national) and with the Helsinki declaration. All patients gave informed consent before enrollment into the study authorized by the National and Regional Ethics Committees.

\section{Study Design}

XEBRA was a prospective, open-label, non-randomized, single-arm, multicenter, observational study run in Hungary. All female patients whose metastatic breast cancer could be treated with the XT protocol according to the summary of product characteristics of the drugs were eligible.

The data after enrollment were prospectively collected within the frame of routine oncology care of metastatic breast cancer (MBC) patients in 11 Hungarian oncology centers. All assessments and interventions were done in compliance with the international and institutional protocols. The choice of therapy was decided by an oncologist team prior to inclusion.

At the first consultation, demographic data (date of birth, height, weight, performance status, menopausal status), the medical history and the breast cancer-specific data (date of diagnosis, initial stage, immune-histological parameters, surgery, radiotherapy and systemic therapy, disease-free interval after adjuvant therapy [DFI], date of detection and localization of metastases) were collected as extracted from the patient files. Thereafter, all the informations on the therapy with the XT regimen including efficacy and adverse events were collected from the patient files.

Follow-up was continued until the disease progression or the patient's death, withdrawal of the consent, loss of contact with the patient or the closure of the study, depending on the earliest event occurred.
The number of completed capecitabine and docetaxel cycles, date of last dose, reason for treatment discontinuation, dose modifications, response to therapy, date of progression and/or death, impact of treatment on initial symptoms and adverse events (AEs) occurring during therapy were registered.

\section{Inclusion and Exclusion Criteria}

The study had no specific inclusion criteria. All the patients could take part in the observational study, who were found suitable to the XT regimen according to the official prescription conditions: HER2-negative MBC patients who have previously received either adjuvant or neoadjuvant chemotherapy with standard regimens containing an anthracycline agent or who have started first-line XT chemotherapy within 3 months prior to enrollment.

The study had no specific exclusion criteria, but the trial excluded patients in whom there was a contraindication to the use of capecitabine included in prescription, such as severe and unexpected reactions to fluoropyrimidine therapy in history, hypersensitivity to fluorouracil, capecitabine, known dihydropyrimidine dehydrogenase (DPD) deficiency, pregnancy and lactation, severe leucopenia, neutropenia, or thrombocytopenia, severe liver injury, severe renal impairment (creatinine clearance below $30 \mathrm{ml} / \mathrm{min}$ ), treatment with sorivudine or chemical analogues, or if there was a contraindication to any drug in the combination.

\section{Study Endpoints}

The primary endpoint was median progression free survival (PFS). PFS was defined as the time between the start of study treatment and the detection of disease progression or death. Secondary endpoints included time to treatment failure (TTF). TTF was defined as the time between the start and stop of all study medication due to any reason including disease progression, toxicity or death of the patient), overall response rate (ORR), clinical benefit rate (CBR), dose modification and mean duration of capecitabine treatment, and its toxicity profile. Serious adverse events (SAEs) were classified according to the current version of the Medical Dictionary for Regulatory Activities (MedDRA).

\section{Statistical Analyses}

Data evaluation of demographics, breast tumor-specific medical history, XT chemotherapy, changes due to treatment, secondary endpoints and adverse events was done using descriptive statistics. The analysis of PFS was performed using the Kaplan-Meier method. 


\section{Results}

\section{Patient- and Tumor-Related Characteristics}

Between December 2012 and December 2013, altogether 46 patients were enrolled into the study from 11 of 15 opened centers. Patient- and tumor-related characteristics were analyzed for 45 eligible patients (Table 1), while 1 additional ineligible patient was included in safety analyses only.

The mean \pm SD age was $58.6 \pm 11.4$ years (median: 59.0 years, range $35-83$ years). Most patients $(n=35$, $79.5 \%)$ were postmenopausal, and $15(33.3 \%)$ were $>65$ years old at enrollment.

The mean \pm SD age at the initial diagnosis of breast cancer was $53.2 \pm 11.2$ years (median: 54.0 years, range: $31-81$ years) of the population, and 22 patients $(48.9 \%$ ) had stage 3 disease at that time. Histological diagnosis was invasive ductal carcinoma in 40 patients $(88.9 \%)$, invasive lobular cancer in 4 cases $(8.9 \%)$, while in $1(2.2 \%)$, mixed carcinoma was found. Three-quarters $(77.8 \%$ ) were estrogen receptor (ER)-positive and $60.0 \%$ progesterone receptor (PR)-positive, 9 (20.5\%) were triple negative. Most patients $(36,80.0 \%)$ underwent

Table 1 Baseline patient and tumor characteristics

\begin{tabular}{|c|c|c|c|}
\hline \multirow[t]{2}{*}{ Characteristics } & & \multicolumn{2}{|c|}{$\begin{array}{l}\text { Patients } \\
(N=45)\end{array}$} \\
\hline & & $\mathrm{N}$ & $\%$ \\
\hline \multirow[t]{4}{*}{ Stage } & 0 & 1 & 2.2 \\
\hline & 1 & 8 & 17.8 \\
\hline & 2 & 14 & 31.1 \\
\hline & 3 & 22 & 48.9 \\
\hline \multirow[t]{2}{*}{ ER } & Negative $(\leq 10 \%)$ & 10 & 22.2 \\
\hline & Positive (>10\%) & 35 & 77.8 \\
\hline \multirow[t]{2}{*}{ PR } & Negative $(\leq 10 \%)$ & 18 & 40.0 \\
\hline & Positive (>10\%) & 27 & 60.0 \\
\hline \multirow[t]{4}{*}{ Disease-free/ recurrence-free period } & $\leq 1$ year & 15 & 33.3 \\
\hline & $>1$ year and $\leq 2$ years & 7 & 15.6 \\
\hline & $>2$ years & 22 & 48.9 \\
\hline & No data available & 1 & 2.2 \\
\hline \multirow[t]{6}{*}{ Localization of metastases } & Bone & 19 & 42.2 \\
\hline & Lung & 18 & 40.0 \\
\hline & Pleura & 13 & 28.9 \\
\hline & Liver & 16 & 35.6 \\
\hline & Skin & 2 & 4.4 \\
\hline & $\begin{array}{l}\text { Other ( } 3 \text { cases: no data } \\
\text { available, } 8 \text { cases: } \\
\text { lymph node) }\end{array}$ & 16 & 38.1 \\
\hline \multirow{4}{*}{$\begin{array}{l}\text { European Cooperative Oncology } \\
\text { Group (ECOG) performance } \\
\text { status score }\end{array}$} & 0 & 26 & 57.8 \\
\hline & 1 & 16 & 35.6 \\
\hline & 2 & 2 & 4.4 \\
\hline & No data available & 1 & 2.2 \\
\hline
\end{tabular}

surgical treatment, and in $34(75.6 \%)$, radiation therapy was performed. All patients received chemotherapy in the adjuvant and/or neoadjuvant setting (Table 2). In one case no data were available. 29 patients $(64.4 \%)$ also received adjuvant endocrine treatment. Half of the patients $(48.9 \%)$ had DFI $>2$ years, and one-third $(33.3 \%)$ showed a DFI $<1$ year.

\section{XT Treatment}

In 27 patients (60\%) capecitabine was orally administered at an initial dose of $1250 \mathrm{mg} / \mathrm{m}^{2}$ twice a day on days $1-14$, followed by one week medication-free period. Due to the observational design of the study, no accurate data were available on 18 patients as regards the dose of capecitabine. At the beginning of the study, $80.0 \%$ of the patients (36 patients) received $75 \mathrm{mg} / \mathrm{m}^{2}$ docetaxel treatment in intravenous infusion once daily on day 1 every 3 weeks, however, for similar reasons, no exact information on the dose of docetaxel was given in 8 cases. Supportive therapy was applied according to institutional protocols.

\section{Efficacy}

The best tumor response achieved was complete remission in 1 case, and partial remission (PR) was obtained in 12 cases $(26.7 \%)$; stable disease occurred in 20 patients $(44.4 \%)$. Disease progression (PD) was reported in 18 cases $(40.0 \%)$. Thus, ORR was $28.9 \%$, while CBR was $73.3 \%$. According to the patient files, initial tumor-related symptoms improved or disappeared in 16 patients (35.6\%), in 19 cases (42.2\%), however, deteriorated or persisted. There was no such data available in 10 patients (Table 3 ).

The median PFS was $9.9 \pm 3.0$ months (95\% CI: 4.1-15.7) (Fig. 1). TTF was $4.6 \pm 5.1$ months on average (median: 3.00 , range: $0-21$ ).

Table 2 Chemotherapeutic regimens applied in the study population in the adjuvant/neoadjuvant setting

\begin{tabular}{ll}
\hline Chemotherapeutic regimens & Number of patients $n=45(\%)$ \\
\hline AC & $3(6.7)$ \\
EC & $3(6.7)$ \\
FAC & $6(13.3)$ \\
FEC & $10(22.2)$ \\
FEC100, then docetaxel & $2(4.4)$ \\
ED & $4(8.9)$ \\
AC, then paclitaxel & $2(4.4)$ \\
TAC & $8(17.8)$ \\
Other & $7(15.6)$ \\
\hline
\end{tabular}


Table 3 Best tumor response and changes in the initial tumor-related symptoms among the included patients during first-line capecitabine-docetaxel therapy

\begin{tabular}{llll}
\hline \multirow{2}{*}{ Response to capecitabine-docetaxel treatment } & \multicolumn{2}{l}{ Patients (N=45) } \\
\cline { 3 - 4 } \cline { 3 - 4 } & & $\mathrm{N}$ & $\%$ \\
\hline \multirow{2}{*}{ Best tumor response } & Complete Remission (CR) & 1 & 2.2 \\
& Partial Remission (PR) & 12 & 26.7 \\
& Stable Disease (SD) & 20 & 44.4 \\
& Progressive Disease (PD) & 12 & 26.7 \\
Tumor-related symptoms & Improved & 14 & 31.1 \\
& Ceased & 2 & 4.4 \\
& Persisted & 17 & 37.8 \\
& Deteriorated & 2 & 4.4 \\
& Unknown & 10 & 22.2 \\
\hline
\end{tabular}

\section{Safety}

The patients received $6.24 \pm 4.80$ cycles of capecitabine and $6.20 \pm 5.12$ cycles of docetaxel on average, but the number of treatment cycles showed high variability (range: $1-26$ and $1-$ 25 , respectively). The reason for treatment discontinuation in most cases was disease progression or physician's decision by considering the risks of therapy continuation (Table 4). Dose reduction was applied for capecitabine in 20 cases $(44.4 \%)$, and docetaxel in 15 cases $(33.3 \%)$, due to $\mathrm{AE}$ in 14 patients $(70.0 \%)$ and 10 patients $(63.7 \%)$, respectively.
The most common adverse events were hand foot syndrome $(26.1 \%)$, neutropenia $(21.7 \%)$, mucositis $(8.7 \%)$, and diarrhea $(6.5 \%)$. During the study, altogether 73 AEs among 33 patients have been reported, of which 13 (17.8\%) were considered as SAE. Fifteen of the reported AEs (20.6\%) were typical for the XT combination treatment, while 21 $(28.8 \%)$ and $26(35.6 \%)$ events were attributed to capecitabine and docetaxel, respectively. The AEs with an incidence of $>5 \%$ was found to be 35 and affected 21 patients $(45.7 \%$ ), as shown in Table 5. Seventeen AEs (23.3\%) led to cessation of therapy, 9 of which were related to capecitabine, and another 8 to docetaxel. Twenty-four (32.9\%) of the AEs lead to reduction of either capecitabine $(n=14)$ or docetaxel $(n=10)$ doses. 52 of the reported AEs (71.2\%) required therapeutic intervention, while $21(28.8 \%)$ not. Most AEs resolved or improved (59 events, $80.8 \%$ ), usually without sequelae (44 events, $60.3 \%$ ). Until study completion the outcome of 14 events $(19.2 \%)$ remained the same or worsened (Table 6).

SAEs are summarized in Table 7. During the study, a total of 13 SAEs were reported in 8 patients. In 4 patients 1 SAE each, in 3 patients 2 SAEs, and in another patient 3 SAEs were reported. According to the consideration of the investigator, 3 SAEs $(23.1 \%)$ were related to the XT combination, 3 other events $(23.1 \%)$, were related to capecitabine, and 2 events $(15.4 \%)$ to docetaxel therapy. The majority of SAEs (8 events, $61.5 \%)$ resolved without sequelae. One docetaxel treatmentrelated SAE (neutropenia) had fatal outcome. Three other patients died during the study; none of these deaths was associated with capecitabine or docetaxel treatment.
Fig. 1 Kaplan-Meier analysis of progression-free survival in patients treated with first-line XT chemotherapy; median $\mathrm{PFS}=9.9 \pm 3.0$ months $(95 \% \mathrm{CI}$ : 4.1-15.7)

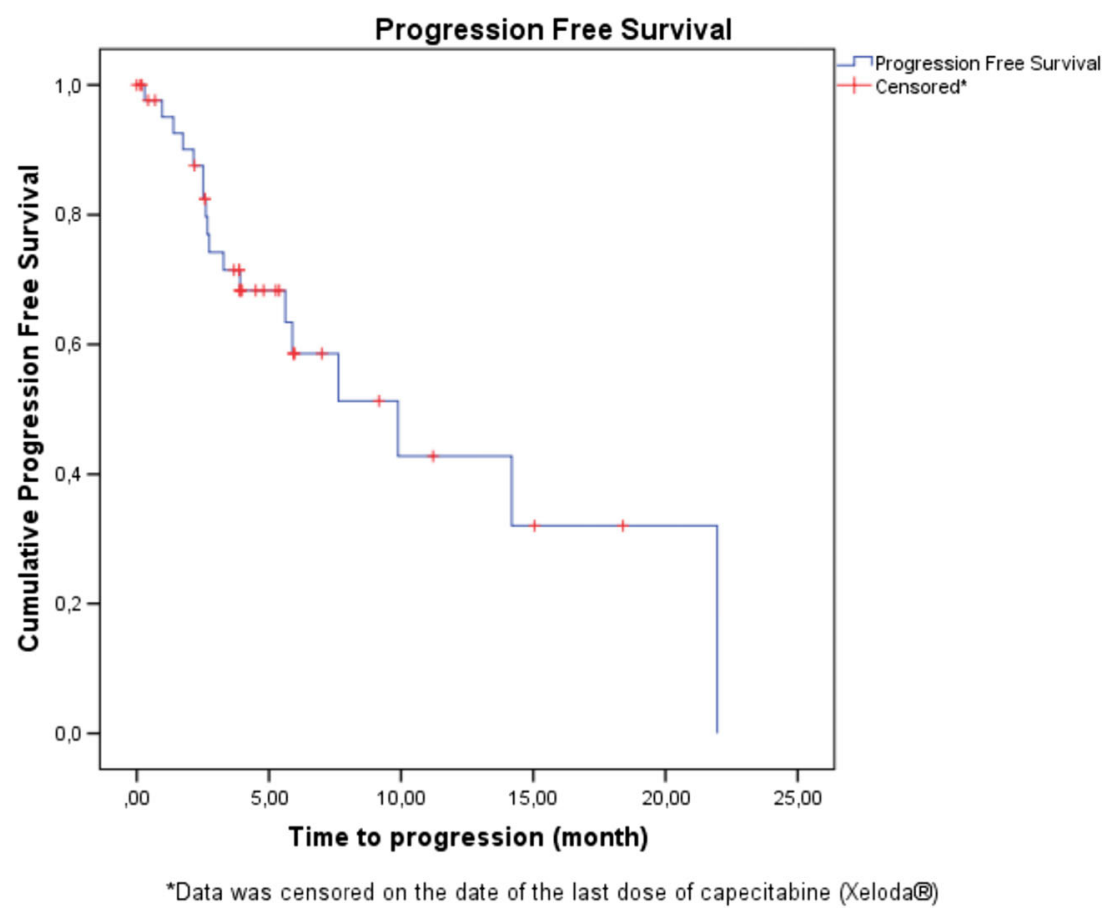


Table 4 Reasons for treatment (capecitabine vs. docetaxel) discontinuation in the patient population

\begin{tabular}{lll}
\hline Reason for treatment discontinuation & \multicolumn{2}{l}{ Number of patients $(\%)$} \\
\cline { 2 - 3 } & Capecitabine & Docetaxel \\
\hline Disease progression & $16(35.6)$ & $12(26.7)$ \\
Death due to other reason (neutropenia) & $1(2.2)$ & $1(2.2)$ \\
Adverse event & $9(20.0)$ & $8(17.8)$ \\
Decision of the physician & $12(26.7)$ & $15(33.3)$ \\
Withdrawal of consent & $2(4.4)$ & $3(6.7)$ \\
The contact with the patient was lost & $3(6.7)$ & $3(6.7)$ \\
Decision of the sponsor & $2(4.4)$ & $1(2.2)$ \\
No data available & $0(0.0)$ & $2(4.4)$ \\
\hline
\end{tabular}

\section{Discussion}

The significant anticancer effect of combined XT therapy was first demonstrated in a phase I trial in patients with advanced solid tumors [8]. The study applied a 3-weekly regimen of capecitabine $1250 \mathrm{mg} / \mathrm{m}^{2}$ twice daily, days $1-14$, and docetaxel $75 \mathrm{mg} / \mathrm{m}^{2}$ on day 1 , which was well tolerated, furthermore, in six patients allowed the delivery of $\geq 23$ cycles. This regimen was then evaluated in the large pivotal phase III trial resulting in a time to tumor progression (TTP) of 6.1 months, indicating that second- or third-line XT therapy is highly effective for patients with anthracycline-pretreated MBC. XT combination was significantly superior to docetaxel monotherapy, with significantly superior ORR, TTP, and OS as compared to single-agent docetaxel [9]. The subsequent randomized trials in first-, second- and third-line settings using the same regimen achieved TTP/PFS of 7.9-10 months, median overall survival (OS) of 16.4-28 months and ORR of $38.9-68 \%$ [10-13]. Despite the differences in patient populations, the regimens and the response criteria applied, our data are comparable with these results.

In our study, dose reduction of capecitabine and docetaxel was necessary in $44.4 \%$ and $33.3 \%$ of the patients, respectively. In the pivotal phase III trial [9] the results of patients undergoing early dose reduction, showed unaltered efficacy of the XT combination. Harvey et al. [14] recommended that in patients older than 60 years, a $25 \%$ reduction of the starting dose should be pondered and that a further decrease in the

Table 5 Adverse events occurring in $>5 \%$ of the cases $(n=46)$

\begin{tabular}{lll}
\hline Adverse event & Number of patients (\%) & Occasion \\
\hline Neutropenia & $10(21.7)$ & 14 \\
Diarrhea & $3(6.5)$ & 4 \\
Mucositis & $4(8.7)$ & 4 \\
Hand-foot syndrome & $12(26.1)$ & 13 \\
\hline
\end{tabular}

dose of docetaxel to $55-60 \mathrm{mg} / \mathrm{m}^{2}$ may lead to further benefit regarding the side effects without adverse impact on survival. These data allowed the determination of the most favorabledose regimen with still high antitumor activity. In phase II clinical trials $[12,15]$ capecitabine $825 \mathrm{mg} / \mathrm{m}^{2}$ twice daily, on days 1-14 plus docetaxel $75 \mathrm{mg} / \mathrm{m}^{2}$ resulted in a median PFS of 5.8-8.5 month, an ORR of 37.4-74\% and a median OS of 15.1-28.6 months. In the study of the Hellenic Oncology Group [16] $950 \mathrm{mg} / \mathrm{m}^{2}$ capecitabine twice daily was combined with docetaxel $75 \mathrm{mg} / \mathrm{m}^{2}$. ORR was $53 \%$, PFS was 11 months and median OS was 35.7 months. Michalaki et al. [17] found a PFS of 8 months, an ORR of $42 \%$ and a median OS of 23 months in patients with MBC, receiving first-line XT therapy of the same regimen. Seidman et al. [18] and Bachelot et al. [19] reported an 8.9-12.4 months PFS, respectively, when applying $1000 \mathrm{mg} / \mathrm{m}^{2}$ capecitabine twice daily and the usual dose of docetaxel; the median OS was 23.3 months. Bachelot et al. detected an ORR of $64 \%$ and a 2-year OS of $68 \%$ [19]. Yu et al. evaluated that capecitabine in a dose of $1000 \mathrm{mg} / \mathrm{m}^{2}$ twice a day on days $1-14$ combined with docetaxel $35 \mathrm{mg} / \mathrm{m}^{2}$ on days 1 and 8 yielded a PFS of 8.3 months [20]. The ORR was $12.27 \%$ and the 1-year median OS was $81 \%$. Gradishar [21] and Blum et al. [22] ascertained that the combination of capecitabine at a reduced dose and 3-weekly or weekly paclitaxel has a high efficacy and a more favorable safety profile.

In our study, neutropenia and hand-foot syndrome (HFS) were the most common adverse events, followed by mucositis and diarrhea. These adverse effects are well known from both the previous studies [7-17] and everyday practice. In the pivotal phase III trial gastrointestinal side effects and HFS occurred more frequently in patients receiving combined chemotherapy [9]. However, myalgia, arthralgia, neutropenic fever and sepsis were more common when docetaxel was used as a single agent. In the studies applying lower doses of capecitabine, HFS and neutropenia were the most common adverse events [17]. At the registered dose, grade 3-4 diarrhea was detected in $18 \%$ of patients [9-11] while in the trials testing a reduced dose of capecitabine [15-17] it was reported in 2-7\% of the cases. At the $1250 \mathrm{mg} / \mathrm{m}^{2}$ twice a day dose of capecitabine, 18 $26 \%$ of the patients developed grade 3 HFS [9-11], whereas

Table 6 The outcome of the adverse events in the ITT population $(\mathrm{n}=46)$

\begin{tabular}{ll}
\hline Outcome of the adverse event & Number of adverse events (\%) \\
\hline Completely recovered & $44(60.3)$ \\
Recovered with sequelae & $4(5.5)$ \\
Improved & $11(15.1)$ \\
Persistent & $7(9.6)$ \\
Deteriorated & $3(4.1)$ \\
Fatal & $4(5.5)$ \\
\hline
\end{tabular}


Table 7 Summary of the serious adverse events reported in the ITT population $(n=46)$

\begin{tabular}{llllll}
\hline \multirow{2}{*}{ Serious adverse event } & \multirow{2}{*}{$\begin{array}{l}\text { Number of the } \\
\text { patients affected (\%) }\end{array}$} & \multicolumn{5}{l}{ Number of serious adverse events } \\
\cline { 4 - 7 } & & Total & Treatment-related & Fatal & Treatment-related fatal \\
\hline Anaemia & $1(2.2)$ & 1 & 1 & 0 & 0 \\
Neutropenia & $3(6.5)$ & 3 & 3 & 1 & 1 \\
Thrombocytopenia & $1(2.2)$ & 1 & 1 & 0 & 0 \\
Heart failure & $1(2.2)$ & 1 & 0 & 0 & 0 \\
Diarrhea & $1(2.2)$ & 1 & 1 & 0 & 0 \\
Disease progression & $3(6.5)$ & 3 & 0 & 3 & 0 \\
Mucositis & $1(2.2)$ & 1 & 1 & 0 & 0 \\
Pneumonia & $1(2.2)$ & 1 & 0 & 0 & 0 \\
Dermatitis & $1(2.2)$ & 1 & 1 & 0 & 0 \\
\hline
\end{tabular}

in the studies examining decreased doses [15-17], 4-13\% only. In general, the safety profile of the XT regimen is better when given at a reduced dose, and side effects are well controlled with either medical interventions or dose reductions.

The aim of our observational study was to collect experiences with the administration of XT chemotherapy in routine practice in Hungarian oncology centres. A limitation of our study was the small size of the population included. Although the study design did not allow the evaluation of the safety, tolerability and efficacy of XT treatment in comparison with a control arm, since these data are well known from large phase II-III clinical studies [9-20], the main goal was the introduction of this new regimen into routine practice. Our findings raise the attention to the importance of appropriate patient selection and toxicity management.

In conclusion, first-line XT therapy effectively improves the PFS of anthracycline-pretreated patients with rapidly progressing HER2-negative breast cancer, visceral metastases and a good physical status. The AEs appearing during treatment are well manageable with modifications in the dose of either capecitabine or docetaxel, significantly improving the tolerability of therapy but without impairing its efficacy.

\section{References}

1. Rich TA, Shepard RC, Mosley ST (2004) Four decades of continuing innovation with fluorouracil: current and future approaches to fluorouracil chemoradiation therapy. J Clin Oncol 22:2214-2232

2. Lockshin A, Danenberg PV (1981) Biochemical factors affecting the tightness of 5-fluorodeoxyuridylate binding to human thymidylate synthetase. Biochem Pharmacol 30:247-257

3. Milano G, Etienne MC, Renée N, Thyss A, Schneider M, Ramaioli A, Demard F (1994) Relationship between fluorouracil systemic exposure and tumor response and patient survival. J Clin Oncol 12:1291-1295

4. Miwa M, Ura M, Nishida M, Sawada N, Ishikawa T, Mori K, Shimma N, Umeda I, Ishitsuka H (1998) Design of a novel oral fluoropyrimidine carbamate, capecitabine, which generates 5- fluorouracil selectively in tumours by enzymes concentrated in human liver and cancer tissue. Eur J Cancer 34:1274-1281

5. Budman DR, Meropol NJ, Reigner B, Creaven PJ, Lichtman SM, Berghorn E, Behr J, Gordon RJ, Osterwalder B, Griffin T (1998) Preliminary studies of a novel oral fluoropyrimidine carbamate: capecitabine. J Clin Oncol 16:1795-1802

6. Sawada N, Ishikawa T, Fukase Y, Nishida M, Yoshikubo T, Ishitsuka H (1998) Induction of thymidine phosphorylase activity and enhancement of capecitabine efficacy by taxol/taxotere in human cancer xenografts. Clin Cancer Res 4:1013-1019

7. Liang X, Yan Y, Wang L, Song G, DI L, Jiang H, Wang C, Li H (2015) First-line chemotherapy with docetaxel plus capecitabine followed by capecitabine or hormone maintenance therapy for the treatment of metastatic breast cancer patients Oncol Lett 9: 987-993

8. Pronk LC, Vasey P, Sparreboom A, Reigner B, Planting AS, Gordon RJ, Osterwalder B, Verweij J, Twelves C (2000) A phase I and pharmacokinetic study of the combination of capecitabine and docetaxel in patients with advanced solid tumours. Br J Cancer 83: 22-29

9. O'Shaughnessy J, Miles D, Vukelja S, Moiseyenko V, Ayoub JP, Cervantes G, Fumoleau P, Jones S, Lui WY, Mauriac L, Twelves C, Van Hazel G, Verma S, Leonard R (2002) Superior survival with capecitabine plus docetaxel combination therapy in anthracyclinepretreated patients with advanced breast cancer: phase III trial results. J Clin Oncol 20:2812-2823

10. Beslija S, Obralic N, Basic H, Tatarevic A, Naila M, Banjin M, Cardzic A, Sosevic A, Pasic A, Ceric T, Salkic B (2006) Randomized trial of sequence vs. combination of capecitabine $(\mathrm{X})$ and docetaxel (T): XT vs. T followed by X after progression as firstline therapy for patients (pts) with metastatic breast cancer (MBC). J Clin Oncol 24(Suppl 18):571

11. Chan S, Romieu G, Huober J, Tubiana-Hulin M, Schneeweiss A, Lluch A, Llombart A, du Bois A, Kreienberg R, Mayordomo JI, Antón A, Harrison M, Jones A, Carrasco E, Thareau Vaury A, Frimodt-Moller B, Fumoleau B (2009) Phase III study of gemcitabine plus docetaxel compared with capecitabine plus docetaxel for anthracycline-pretreated patients with metastatic breast cancer. J Clin Oncol 27:1753-1760

12. Buzdar AU, Xu B, Digumarti R, Goedhals L, Hu X, Semiglazov V, Cheporov S, Gotovkin E, Hoersch S, Rittweger K, Miles DW, O'Shaughnessy J, Tjulandin S, NO16853 trial group (2012) Randomized phase II non-inferiority study (NO16853) of two different doses of capecitabine in combination with docetaxel for locally advanced/metastatic breast cancer. Ann Oncol 23:589-597

13. Vici P, Giotta F, Di Lauro L, Sergi D, Vizza E, Mariani L, Latorre A, Pizzuti L, D'Amico C, Giannarelli D, Colucci G (2011) A multicenter phase II randomized trial of docetaxel/gemcitabine versus 
docetaxel/capecitabine as first-line treatment for advanced breast cancer: a Gruppo Oncologico Italia Meridionale study. Oncology 81:230-236

14. Harvey V, Mouridsen H, Semiglazov V, Jakobsen E, Voznyi E, Robinson BA, Groult V, Murawsky M, Cold S (2006) Phase III trial comparing three doses of docetaxel for second-line treatment of advanced breast cancer. J Clin Oncol 24:4963-4970

15. Soto C, Torrecillas L, Reyes S, Ramirez M, Perez L, Cervantes G, Gonzalez F, Tellez E, Cortes P, Benitez H (2006) Capecitabine (X) and taxanes in patients (pts) with anthracycline-pretreated metastatic breast cancer (MBC): sequential vs. combined therapy results from a MOSG randomized phase III trial. J Clin Oncol 24 (Suppl 18): 570

16. Mavroudis D, Papakotoulas P, Ardavanis A, Syrigos K, Kakolyris S, Ziras N, Kouroussis C, Malamos N, Polyzos A, Christophyllakis C, Kentepozidis N, Georgoulias V, Breast Cancer Investigators of the Hellenic Oncology Research Group (2010) Randomized phase III trial comparing docetaxel plus epirubicin versus docetaxel plus capecitabine as firstline treatment in women with advanced breast cancer. Ann Oncol 21:48-54

17. Michalaki V, Gennatas S, Gennatas K (2009) Low-dose capecitabine plus docetaxel as first-line therapy for metastatic breast cancer: phase II results. Anti-Cancer Drugs 20:204-207

18. Seidman AD, Brufsky A, Ansari RH, Hart LL, Stein RS, Schwartzberg LS, Stewart JF, Russell CA, Chen SC, Fein LE, De
La Cruz Vargas JA, Kim SB, Cavalheiro J, Zhao L, Gill JF, Obasaju CK, Orlando M, Tai DF (2011) Phase III trial of gemcitabine plus docetaxel versus capecitabine plus docetaxel with planned crossover to the alternate single agent in metastatic breast cancer. Ann Oncol 22:1094-1101

19. Bachelot T, Bajard A, Ray-Coquard I, Provencal J, Coeffic D, Agostini C, Boisseau M, Kaphan R, Dramais D, Oprea C, FerriDessens RM, Guastalla JP, Perol D (2011) Final results of ERASME-4: a randomized trial of first-line docetaxel plus either capecitabine or epirubicin for metastatic breast cancer. Oncology 80:262-268

20. Yu J, Lj DI, Song G, Che L, Hf J, Zhu YI, Liang X, Jia J, Zhang J, Yang H, Wang XI, Xn Z, Ren J (2011) Randomized clinical casecontrol trial for the comparison of docetaxel plus thiotepa versus docetaxel plus capecitabine in patients with metastatic breast cancer. Beijing Da Xue Xue Bao 43:151-156

21. Gradishar WJ, Meza LA, Amin B, Samid D, Hill T, Chen YM, Lower EE, Marcom PK (2004) Capecitabine plus paclitaxel as front-line combination therapy for metastatic breast cancer: a multicenter phase II study. J Clin Oncol 22:2321-2327

22. Blum JL, Dees EC, Chacko A, Doane L, Ethirajan S, Hopkins J, McMahon R, Merten S, Negron A, Neubauer M, Ilegbodu D, Boehm KA, Asmar L, O’Shaughnessy JA (2006) Phase II trial of capecitabine and weekly paclitaxel as first-line therapy for metastatic breast cancer. J Clin Oncol 24:4384-4390 